\title{
Significant Foundation Techniques for Education: A Critical Analysis
}

\author{
PHILOTHEOS LOKKAS ${ }^{1}$, EMMANOUIL PAPADIMITRIOU ${ }^{2}$, NIKOLAOS ALAMANIS ${ }^{3}$, GRIGORIOS \\ PAPAGEORGIOU $^{3}$, DIMITRIOS CHRISTODOULOU ${ }^{4}$, and THEODOROS CHRISANIDIS ${ }^{5}$ \\ ${ }^{1}$ Emeritus Professor, University of Thessaly, GREECE \\ ${ }^{2}$ Undergraduate Student, P.S. of Civil Engineering T.E, University of Thessaly, GREECE \\ ${ }^{3}$ General Department of Larissa, University of Thessaly, GREECE \\ ${ }^{4}$ Environmeral Department of Larissa, University of Thessaly, GREECE \\ ${ }^{5} \mathrm{PhD}$ Civil Engineer, Post-Doctoral Researcher (Dr., MSc DIC) \\ *Corresponding Author: p.lokkas@uth.gr
}

\begin{abstract}
In engineering, the foundation is a special element of a building. It is the connecting part with the soil, which transfers loads from the structure to the ground, so that they are distributed on a wider area, thus avoiding high levels of soil stresses. Furthermore, they help the structure to withstand various natural forces like earthquakes, floods, tornadoes, and also to anchor the structure into the ground, thus increasing its stability. Over time, people aim to build elaborate structures, first to facilitate the standard living and then, utilizing this primary purpose, to make a substantial contribution to the progress and development of science, through the discovery of new methods. This work aims to briefly record, analyze, and comment on special cases of building foundations and infrastructure projects that are in line with modern requirements of research and technology. The work furthermore presents the advantages of static and seismic behavior of the foundations which may present significant structures over similar ones of the same or smaller scale. There was an effort to develop and comment on the information which explains the general nature of the foundations with their evolutionary activity. These concepts, combined with a description of the typical building or infrastructure project, with their characteristics may be a powerful tool not only for future constructions and research but mainly for education. The work also emphasizes the connection between theory and practice.
\end{abstract}

Key-Words: - Foundation, Superstructures, Geotechnical Education, Soil mechanics, Infrastructure Received: July 10, 2020. Revised: December 13, 2020. Accepted: February 5, 2021. Published: February 15, 2021.

\section{Introduction}

The vertical bearing elements of the superstructures (columns, walls) can carry significant loads, given the high strength of their material (steelreinforced concrete). These loads, if delivered directly to the ground, whose strength is much smaller (two or three orders of magnitude), are considered to create many problems, such as severe deformation of the soil and construction, subsidence, etc.

To deal with these problems, in each construction a special group of elements is designed and constructed, which is used for the safe transfer of superstructure loads to the ground $[1,2,3]$. This part of the construction is called the "foundation".

The term "foundation" means the lowest element of a structure, which is not only the base on which the structure is supported but also the part that is in direct contact with the ground and transfers loads to it [3].

The foundation constitutes the starting step for each construction project. This step can be usually realized through a profound knowledge of Statics, Hydromechanics, and Strength of Materials. The field of Soil Engineering is also of special importance for understanding the theoretical background of foundation projects $[4,5]$. Furthermore, knowledge and technological experience from the areas of Metal, Wooden, and Reinforced Concrete Structures are also required both for the foundation and design procedure of a superstructure. The possession of basic knowledge from other areas of Civil Engineering science facilitates both the formulation of possible problems and the understanding of their extent.

In conclusion, the fundamental usage of any substructure is the safe transfer of loads coming from superstructure directly on the earth where it is based, in such a way as not to cause overload both on the ground (resulting in excessive deformation) and the structural elements of the project [6]. For this reason, a foundation requires a proper design, i.e. precise selection of its type and layout, as well as careful work, i.e. artful and functionally correct construction configuration $[6,7]$.

The over structure along with the foundation and its underneath ground, form a firm packet which is the building. All kinds of loads that a structure can carry are transferred indirectly or directly through 
columns on the foundations. As a result, the ground reacts [3]. The reactions of soil cause stresses both on the ground from which it is deformed, as well as on the load-bearing elements of the structure. The deformations are initially elastic, but as the stresses increase, they become plastic until break. These results in the receding of the soil or foundation surface (subsidence), which increases as the stresses increase, reaching its maximum value at break.

There are, however, cases where the local conditions for a foundation, are very special. Two examples of such cases are depicted in Venice, where the water of the canals is salty; one in an earlier period (Fig. 1) and another in a subsequent, more or less recent time (Fig. 2).

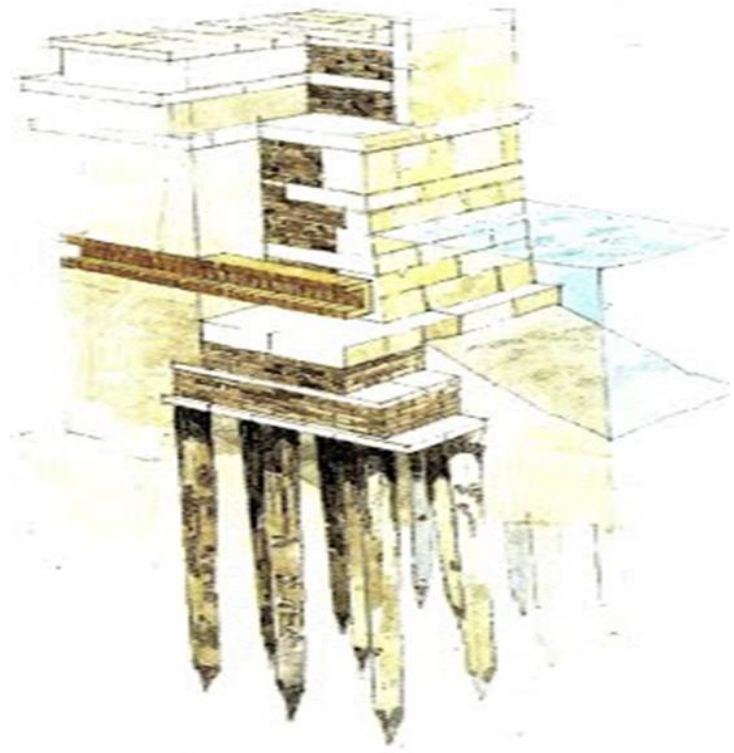

Fig. 1 Building Foundation in Venice, in an earlier period [8]

Since the phenomenon of subsidence cannot be avoided, the purpose of design along with the relevant dimensioning of the foundations is to:

- Limit subsidence to acceptable levels for superstructure,

- Maintain invariable initial distance between all the foundations (avoidance of differential subsidence),

- Exclude any fracture deformations, such as a ground fracture $[3,10]$.

For a foundation to be characterized as structurally correct, the following conditions should be met:

(a) It should be safe against possible failure of the ground, on which it rests [3],

(b) It should not undergo excessive loads [6],

(c) It should always be designed considering the environmental factors (frost and wind action, groundwater, earthquakes, etc.) along with other parameters (loose soils, adjacent buildings, excavations, etc.) [6] and

(d) Be economically feasible to the cost of the overall construction [7].

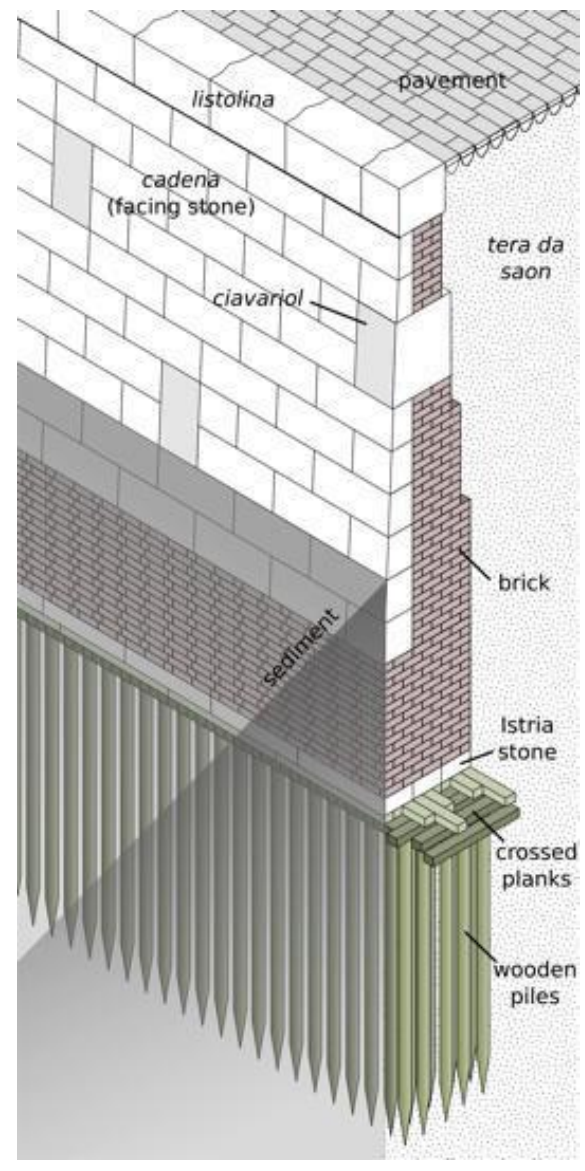

Fig. 2 Parts of a typical canal wall [9]

This work aims to analyze and discuss special cases of building foundations and infrastructure projects. Obviously, however, each case is unique and to ensure an ideal behavior of the construction, the design must be developed according to the data provided by nature, following the existing scientific theory and experience for the installation.

\section{Literature review}

In the part of the introduction, the bibliographic sources 1, 2, 3, 4, 5, 6 were useful and helped the fundamental data to be collected. In particular, the source 3 and 10 was necessary for the analysis of the subsidence phenomenon while references 6 and 7 provide a holistic criterion of whether a structure can be characterized as structurally correct. Sources 8,9 were used to obtain the appropriate images.

The description and reference of applied techniques in old times, especially in ancient Greece was given through bibliography 11. Furthermore, 
source 11 in combination with 12 helped in the analysis of Roman architecture and wooden infrastructure, during the Roman Empire along with the first Industrial Revolution.

The rest of the literature, which is included in the Historical perspective, was used to diagnose technical methods, both in ancient times and recent years, such as bibliographic sources 13,14 and 15 .

Section 3 was thus established in order to clarify some technical projects, such as:

Infrastructure works, which are cosmic projects, with a widely accepted difficulty, in their category, in terms of spatial placement, design and construction,

Building projects, which, already from the beginning, had peculiarities, in terms of the project infrastructure and the construction of the superstructure, including the social factors that affect the entity of each technical project.

In particular, to achieve a more specific analysis, in section 3.1.1, the sources used for the extraction of textual roots are $16,17,19,20,21,23,25$ while from 18 and 22 only photographic material was taken. In section 3.1.2, the bibliographic sources 17, 18, 26, 27 were used, from which both the text part and the part of the images were extracted. In general, the bibliographic source 24 was used in the first three sub unities of infrastructure projects, from which both information and some image material were obtained.

In the same way, sub-unities 3.1.3, 3.1.4, and 3.1.5 were organized using sources $3,6,28$, and 29 for the first, while 30 and 31 for the last two respectively. For the exemplary building projects in section 3.2.1, the sources $32,34,37$, and 38 were used for the extraction of information while the photographic material was taken from 33. In section 3.2.2 the sources 37, 39, 40 served for text enrichment while sources 35 and 36 were used in the development of both works. References 41-44 were selected to present the most modern methods for calculating slope and embankment displacements in general.

In the conclusions, the bibliographies 45 up to 48 were selected, because their information was generally applicable for both cases of foundation so that the support of these gigantic buildings could be made structurally feasible.

At the same time, the literature references 49 and 50 were selected on the one hand for the rare and original construction described in [49] and on the other hand for the High-Performance Concretes that strengthen the foundation of important constructions that are clearly mentioned in [50].

Finally, the multitude of bibliographic sources for photographic material aims to highlight the vividness of the presented textual approach.
The results of the research demonstrate the important strategies selected for the study of the foundations presented in the above work as well as the advanced technology used during their construction. At the same time, a critical analysis was attempted that presents the advantages of the remarkable way of establishing the above projects compared to the "classical" infrastructure projects taught in the respective schools of engineering.

In this work the bibliographic review presents the importance of each article or book that appears in the bibliography. It should be noted that each publication exposes a specific work, but does not refer to other works. On the contrary, for the first time such concentrated material is gathered with information and photos from special cases of building foundations and infrastructure projects in a single work. This work differs from those of other researchers not only in terms of the volume of information but also in terms of its didactic character.

This analysis leads us to more modern research teaching methods that help students gain a significant background in high technology. Therefore, the importance of this research lies in the synthesis and analysis of information on the construction of foundations with "innovative techniques and methods" which may be a useful tool on the teaching and education of students in the courses of soil engineering, supports, and foundations. The final result of the research contributes to the acquisition of deeper knowledge and better assessment of the issues involved in it. »

\section{Model-Methodology}

The model to be developed, in other words, the procedure to be followed in this work, consists of three main steps:

The historical background, which presents techniques and methods used in the past, for comparison with modern innovative techniques and methods.

Then follows the search for information, emphasizing the research nature, combined with critical analysis.

In the Literature Review (presented separately in section 2), consisting the final stage of development, a synthesis of information, its analysis, and a comparison with used bibliographic references are pointed out.

\subsection{Historical perspective}

The development of cities-states, the cooperation of their inhabitants on various issues, and the needs 
of survival have created since ancient times the environment in which man should have engineered solutions in order to either survive or be imposed. In this context, the first appearance of deep foundations is realized. This appearance is initially recorded in the form of wooden piles in various countries. In ancient Greece, the first use should be attributed to the development of shipping, which led to the construction of ports and facilities in areas with problematic subsoil [11].

The use of wooden piles was similarly identified, as reported in the city of Venice for mainly defensive purposes against the invaders of the Roman Empire. A similar example is the city of Amsterdam in the Netherlands, whose construction dates back to the $11^{\text {th }}$ century, while similar but smaller-scale constructions can be found in the same time at lakes in Switzerland [11, 12].

An important reference is the ancient Athenian building methodology, regarding the choice of the space in which an ancient building may be erected.

Around the end of $8^{\text {th }}$ century B.C., the Greeks were already aware that between the two directions of a seismic behaviour, the most hazardous was the horizontal one [13].

The early efforts, after which there was a witness to this, directed to fasten the building via wooden or metal bars which were inserted into the material. These solutions, in the early period, were followed by an overall support of the structure by putting transitional elements, the so called orthostatae [13, 14].

In the Roman architecture, orthostatae were already built in different cross-sections. However, the size was not standard, and therefore, in the various examples, all the projections were also different [14].

In the $6^{\text {th }}$ century B.C., the ruins of the Hanging Gardens of Babylon, show that the main structural system was probably supported by piers, the tops of which were connected through arches $[13,14]$.

In the world-wide special city of Venice, followed a somehow awkward structural way, according to which, the footings of the external facade walls of the building, facing the canals, were supported on piles embodied in the soil, while the corresponding to the internal walls were resting on the ground $[14,15]$.

Some authors claim that the origin of a such irrational system of construction has to be correlated with the appearance of 2 totally unlike ways of building: the first, old one, during which the city may be characterized as 'urbanized', where the ground was compacted by driving piles into it before buildings were undertaken, and a later, developed gradually, during which buildings were erected [13, $15]$.
In the light of what has been said, we can conclude that in the area consisting of the former provinces of Europe, which, in that period fell under the Roman Empire, the era, spanning the appearance of the substructures until the beginning of the Revolution in industry [12], the achieved progress on the techniques of structural foundations along with the criteria for their sizing has been limited, due to the following reasons:

- Ignorance of evaluating the maximum strength of the soil.

- The science of structural mechanics was not yet adequately developed.

- The means available for site investigation were also inadequate.

\subsection{Methodology}

An extensive analysis of the general issues on Foundations necessitates mentioning the methodology of application and design. For a successful mass development, it is advisable to set the goal, through specific topics to be explored. There are two things which are absolutely necessary for someone to become a successful engineer: a) a deep knowledge of scientific principles and b) his own relevant experience. The principle of the applied methodology lies in the analysis of some extremely interesting techniques on the foundations in the older time.

Then a distinction is made between applied foundations in infrastructure projects such as bridges and dams (The Øresund Bridge - Denmark \& Sweden, The Bangabandhu Jamuna Bridge Bangladesh, Rio Antirio Bridge - Greece) but also in building projects (Trump International Hotel and Tower - Illinois - USA, Burj Khalifa - Dubai - UAE, Meru as a Hindu Sacred Building Architecture). Through this analysis, the demonstration of various forms of foundations presented in the following unities, which were originally for their time, was achieved. Utilizing the information coming out, from further analysis, it will be possible to draw some deliberate and targeted conclusions.

The specific targeted development of this topic covers the existence and evolution of technologically innovative methods of application in the field of foundations in general, but also particularly in building and infrastructure projects.

However, what makes this work important is the way in which its research character is highlighted, i.e.:

- The general and more specific search on the history of the foundations,

- their evolution over the years and 
- their consolidation as a part of the construction necessary and basic for supporting the rest of the structure

- to encourage the young students and preserve the profession of geotechnical engineering.

These targets constitute the triptych of purpose and expediency of this effort. A confirmation of its authenticity is a brief presentation and study of some significant works because of bibliographic sources and investigation.

The respective report of projects constitutes a separate and more specific indication on the progress of the foundations, something that, at least in the previous years, seemed utopian for the applied technology of that period. This extensive study leads to proposals and conclusions useful for problems or improvements that arose in each case, both at the level of design and construction, but also at the stage of maintenance and management. Finally, this paper may be valuable for the education and training of future geotechnical engineers.

\section{Results - Important cases of foundation all over the world}

\subsection{Infrastructure works}

The infrastructure of a country usually reflects the social and historical development and characterizes the level of collective effort. The forms and functions of infrastructures contribute to understand the quality of life and differences between regions, groups of people, and cultures.

An infrastructure work consists of various structures, buildings, pipelines, roads, orchards, bridges, tunnels, and networks. An equally important variable is the "cost" of the materials and human labor, along with all the official and unofficial obligations for the operation of these systems.

\subsubsection{The Øresund Bridge}

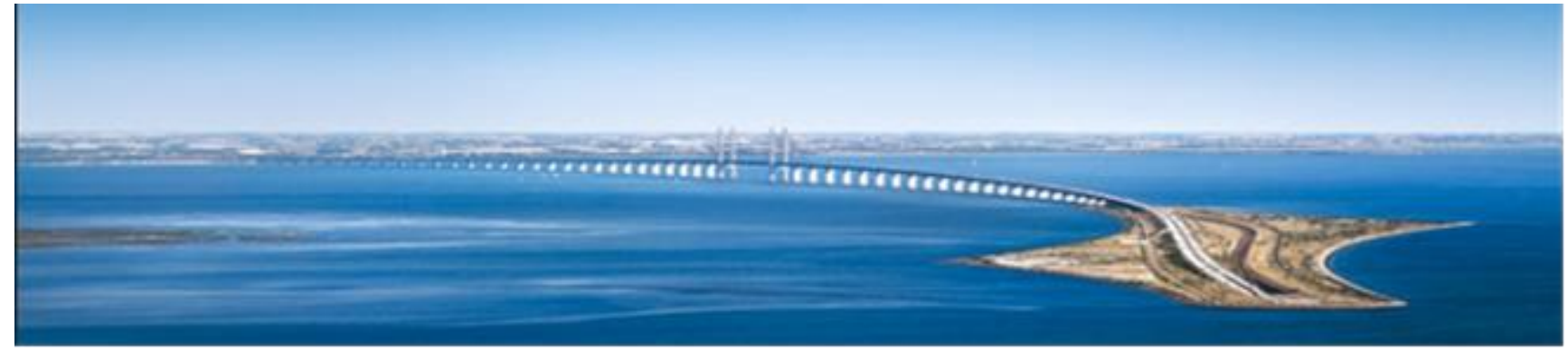

Fig. 3 View of Øresund Bridge [16]

The Øresund Bridge, (Fig. 3), in Sweden, consisting a link with Denmark, consists of three main parts:

1. A western component bridge of length $3014 \mathrm{~m}$,

2. A central part of high bridge $1092 \mathrm{~m}$, which is 'cable-stayed', the central span of which, $490 \mathrm{~m}$, crosses the channel Flinterenden that is used for navigation, with a clearance of $57 \mathrm{~m}$, and

3. An eastern component bridge of $3739 \mathrm{~m}$, which is an approach to Lernacken, driving from the high bridge under the ground $[17,18,19]$.

The superstructure of the bridge is made of a composite steel-concrete structural way using truss girders. There are two decks: the upper one consists of a 4-lane motorway, while the lower accommodates a 2-track railway. The bridge is 'cable-staying' and for its kind, is the largest in the world, providing both motorway and train traffic [17, 18, 20].

The foundation design could be characterized as a large-scale prefabrication of mega-size elements. However, the soil conditions faced locally in the area, were totally different and resulted in various alterations of the initial concept.

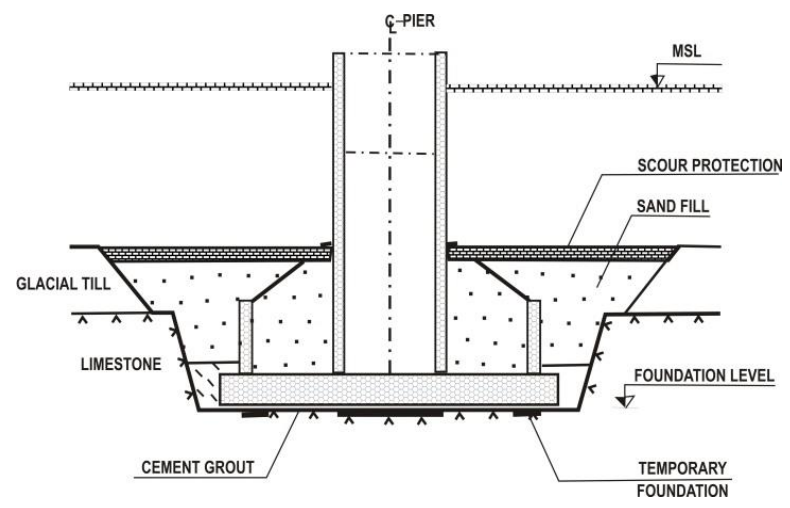

Figure 4. Bridge pier foundation [18]

Fig. 4 depicts without dimensions or details, the principle of a typical pier foundation.

The great dare for this work was to optimize the foundations of the bridge to opose an impact loading of a ship on many piers $[19,21]$. 
Fig. 5 depicts the longitudinal profile of the bridge, where the design principles and geotechnical soilstructure were considered [18].

In the bridge alignment the Øresund is shallow, with an average water depth not more than $8 \mathrm{~m}$.
The stratification of the ground that forms the bottom of the sea, is maily postglacial sands, with an average thickness of not more than $1 \mathrm{~m}$, along with some places of thin layers with peat or organic mud.

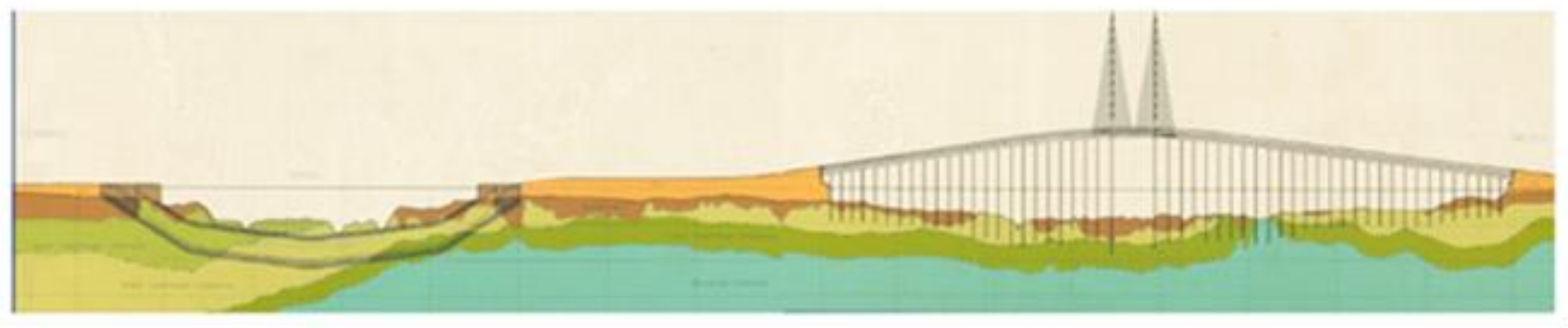

Fig. 5 A typical longwise profile form Cobenhagen to Malmoe in alignment (Light brown $=$ fill, brown $=$ glacial deposits \& green, yellow, green = Upper, Middle and Lower Copenhagen limestone Units, blue = Bryozoan limestone) [18]

The geotechnical design basis was checked up through 1 borehole along with 4 DTH soundings in the local area of each pylon and pier caisson [20,21]. In the research of ground, special care was given to control that no one of the characteristics below could exist, as they might create undesirable situations on the design of the foundation:

- Fissured or highly crushed limestone.

- Spacious zones of unlithified limestone.

- Concavities owing to karstic limestone.

- Mild deposits in compression between mounds of bryozoans [18, 20, 21].

A series of geophysical logs was executed in every borehole and sound hole. These logs contained caliper, natural gamma radiation, neutron porosity, gamma density, as well as deep and shallow guard resistivity. A flow log was also carried out in all core drilled boreholes. The geophysical marker horizons defined in the pre-tender investigations [24], may facilitate, in general, the interpretation of the ground stratification.

The size of the project along with the design of the piers and pylons was the main geotechnical challenge for great vessel impact loads. The basic subjects to be considered were the effect of weak horizontal layers along with that of the limestone's peak/residual strength on the load bearing capacity of both the pier and pylon foundations [19, 20,21].

A very essential design-choice was the $2 \mathrm{~km}^{2}$ artificial island, which is the access of the Drogden tunnel (Fig. 6), connecting the bridge with Denmark. This solution was considered necessary for this part of the project to prevent the hypothetical risk of bridge-aeroplane collisions due to proximity of the Copenhagen Airport.

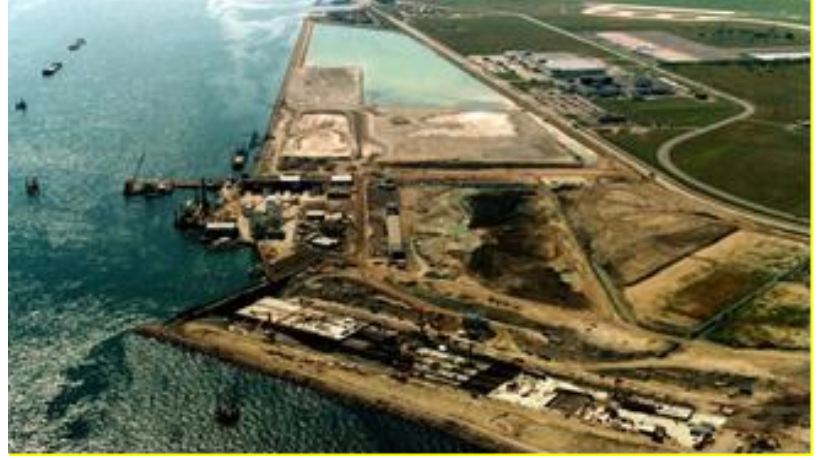

Fig. 6 Tunnel of the Øresund Bridge [22]

Aiming at a reliable estimation of the footings' bearing capacity, the following scientific chapters, mainly from Mechanics of materials were used:

- Kinematically admissible solutions, theory of plasticity,

- Limit Equilibrium and Finite Element Analysis.

The estimation of the footings bearing capacity, was initially dependant on the friction of limestone. Eventually there was a calculation via 3 methods for a case with frictional material and highly eccentric load [19, 21, and 23].

The bearing capacity on a failure mechanism for foundations was eventually estimated by the theory of plasticity. Then, the same theory had to determine whether the peak or the residual strength parameter should be applied to calculate the footing bearing capacity [18, 21, and 23].

Two computer programs were used for the above purpose: a) the BEAST program, based on the method of slices and b) the WEDGE3 program, developed as a part of the studies carried out. The results of both programs were comparable with the other methods [25]. 


\subsubsection{The Bangabandhu Jamuna Bridge}

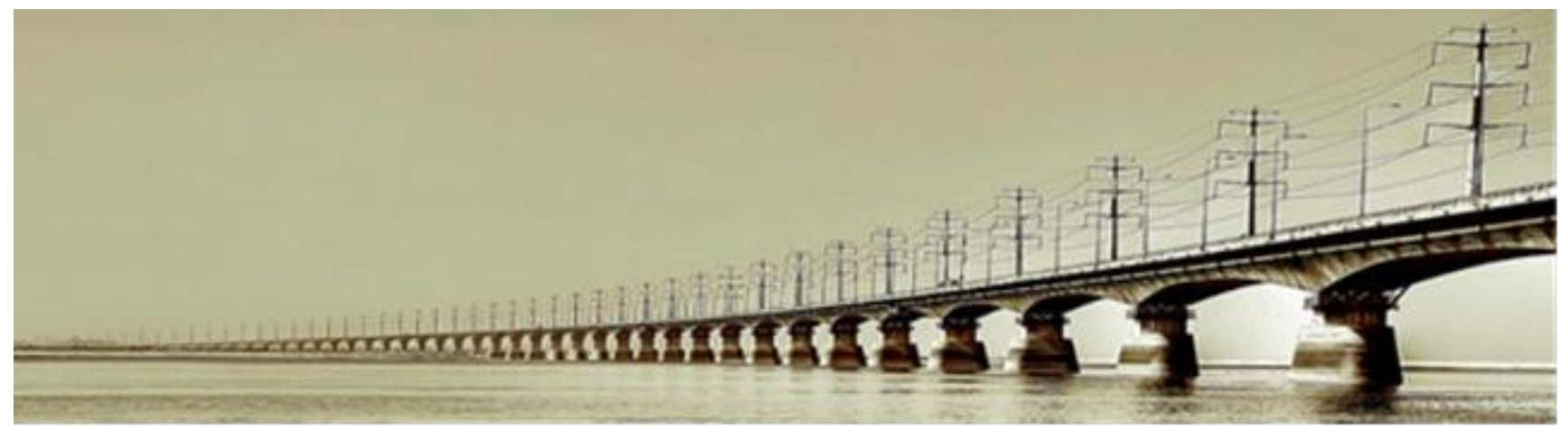

Fig. 7 The Bangabandhu Jamuna Bridge [27]

The Bangabandhu Jamuna Multipurpose Bridge (Fig. 7) in Bangladesh, consists of 49 similar spans. Each one of them is about $100 \mathrm{~m}$ long and carries a 4-lane road, a one-meter width railway as well as a transmission line of $230-\mathrm{kV}$ electrical power along with a gas pipeline of $760 \mathrm{~mm}$ diameter [17, 18].
The main constructional concept of the project was based on the use of recurrent similar parts of the bridge, which constituted the necessary elements for each span. Of course, there was a massive production of the elements, which were erected in situ [18, 26].

A typical pile layout of bridge is depicted in Fig. 8.

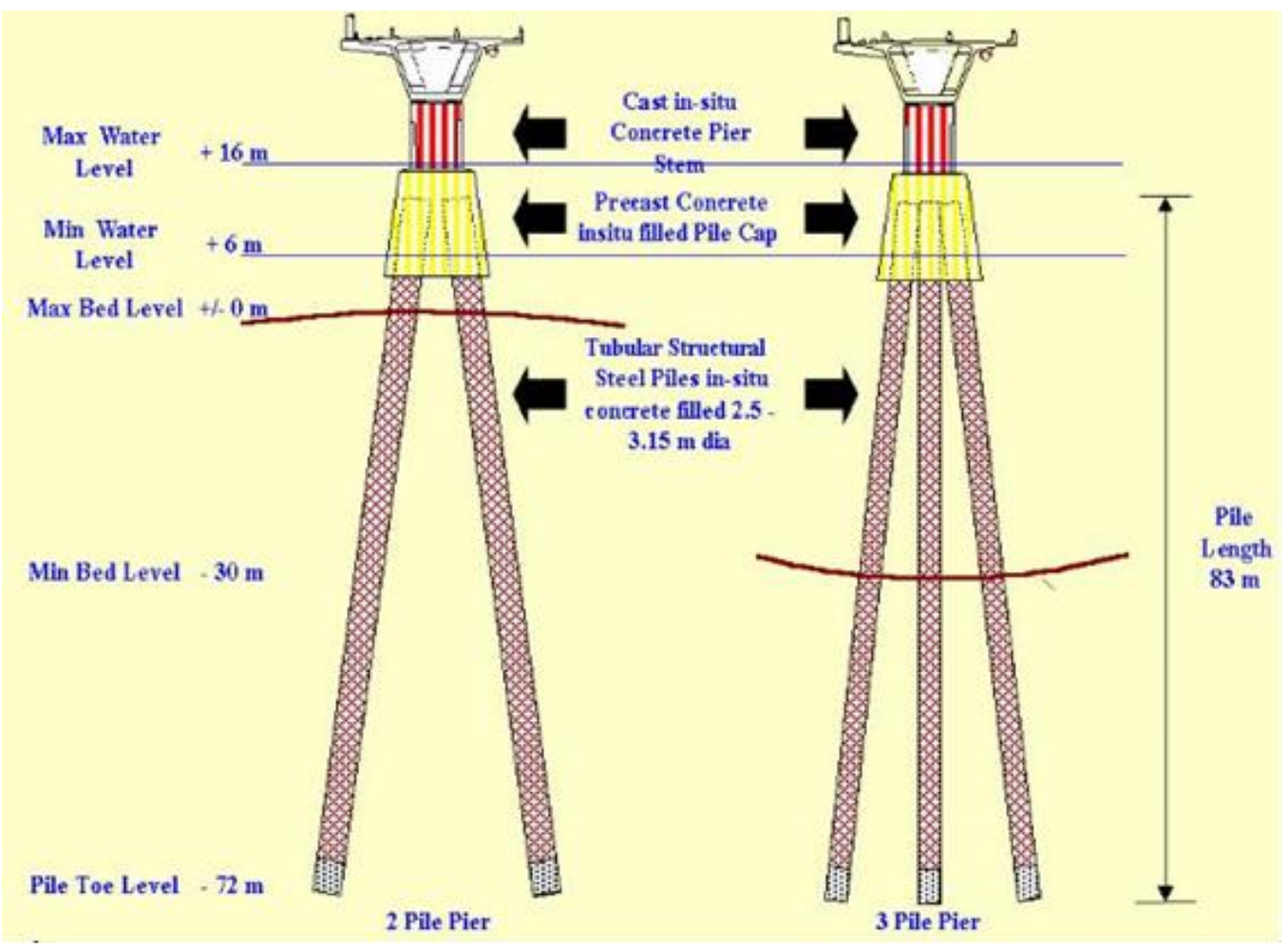

Fig. 8 Foundation's pile layout [18]

The launched concrete superstructure consisted of pre-cast segments supported on piers. The segments have been built by the so called 'balanced cantilever method'. The piers in turn were rested on tubular steel piles of about 80 meters long, embodied into the river bed $[17,26]$.

The total number of piers is 50 . The 21 of them consist of 3 pile-groups, of $2.5 \mathrm{~m}$ diameter, while the rest 29 piers consist of 2 pile-groups only, of $3.15 \mathrm{~m}$ diameter. The wall thicknesses of piles varied from 40 to $60 \mathrm{~mm}$. On the top of piles, a pre-cast concrete shell cone (depicted in Fig. 8 in yellow) of $5 \mathrm{~m}$ height, was cast in-situ [17, 18, and 26].

Having driven the pile at its correct depth in the bottom, a sufficient volume of tremie concrete was poured at its toe level using airlift. The stiffness 
between soil and concrete was increased by pumping grout into the pile toe under 40 bar pressure, thus retaining absolute and differential settlements to a minimum level $[18,26]$.

A brief summary of the main advantages on the use of this kind of foundation for this bridge is the following:

- Affordable construction,
- Improved lateral stiffness of piles compared to vertical ones,

- Strength against liquefaction during a seismic activity or violent river flow, and

- Reliable and fast construction.

The whole of 121 piles were accurately driven into the ground between October 1995 and July 1996.

\subsubsection{Rio - Antirrio Bridge}

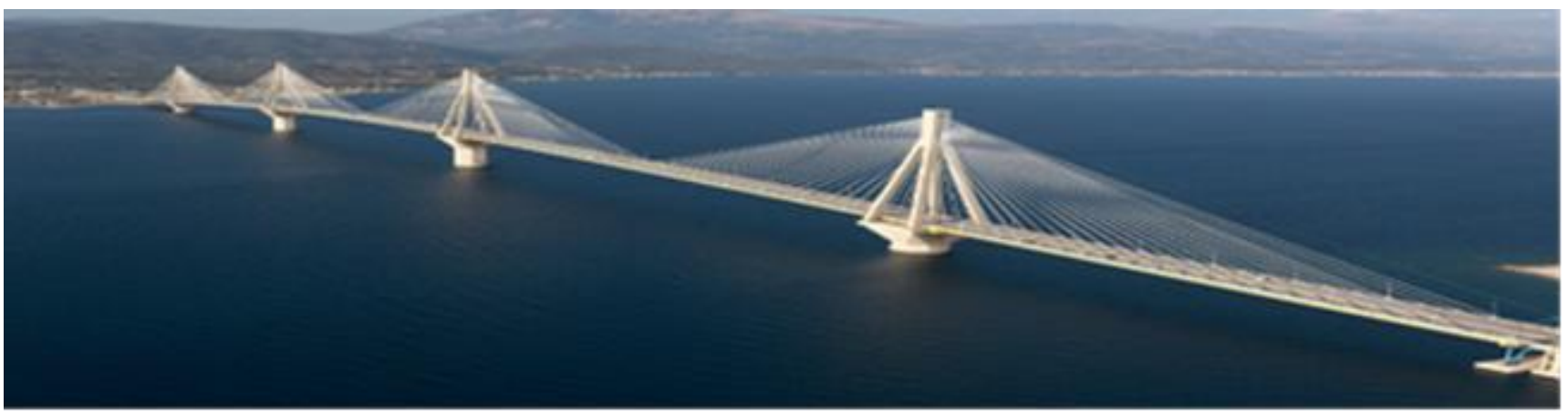

Fig. 9 Rio - Antirrio Bridge [28]

Many innovative studies and offshore construction methods have been used to make a reality this unique multi-opening cable-stayed bridge in Greece (Fig. 9).

It is worth noting among others, the adoption and application of this kind of bridge, i.e. a cable-stayed, in which the deck is supported from cables connected directly to pylon towers. This solution is applied in an area where the sea bed is soft and therefore the foundation of the four towers, spread along a length of 2,252 m (Fig. 10), should be a fully reinforced bottom. The existence of a local earthquake fault, equipped the bridge with a tremendous system of damping, while the cables are controlled by special anti-seismic devices and the expansion joints can absorb great displacements, that may appear both along the length and transversely $[6,29]$.

The head of the design and construction team was the 'Vinci' French company in co-operation with Aktor, J\&P, and Athena construction companies, the largest and more trusted in Greece.

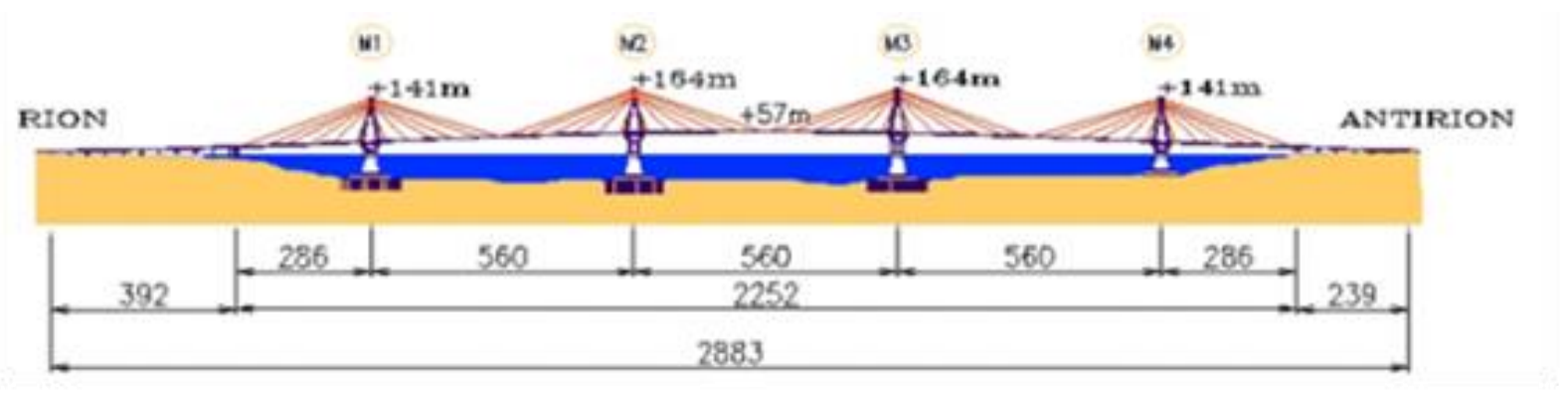

Fig. 10 Bridge layout [29]

Regarding the foundation, from the load-bearing capacity point of view, alternative systems with their respective advantages in terms of rationalization of construction such as costs, feasibility, and technical perfection were examined. The analysis made clear that a shallow foundation had to be applied, under the term that a significant improvement of the first 20 meters of soil would be possible [29].

The extremely loose sea-bed, forced the engineers to apply a special foundation in the following steps:
Depending on the local soil conditions, a number of 110-200 hollow metal pipes, 25 to $30 \mathrm{~m}$ in length and $2 \mathrm{~m}$ in diameter, were inserted into the bottom at distances of 7 meters between them [6, 28] (Fig. 11 left). Then a layer of gravel 3 meters thick was carefully laid covering these implants.

The foundation, consisting of 32 chambers, made of reinforced concrete and forming a huge footing with a diameter of 90 meters, was based on the gravel layer $[28,29]$. 
A cone (Fig. 11 right), of 38 to $26 \mathrm{~m}$ diameter was the base of the pedestal, the top of which was formed to an octagonal structure and an inverted pyramid about 15 meters high (pedestal head) [29]. Each pillar consisted of a square base of 38 meters (pillar base) and four reinforced concrete legs [28, 29].

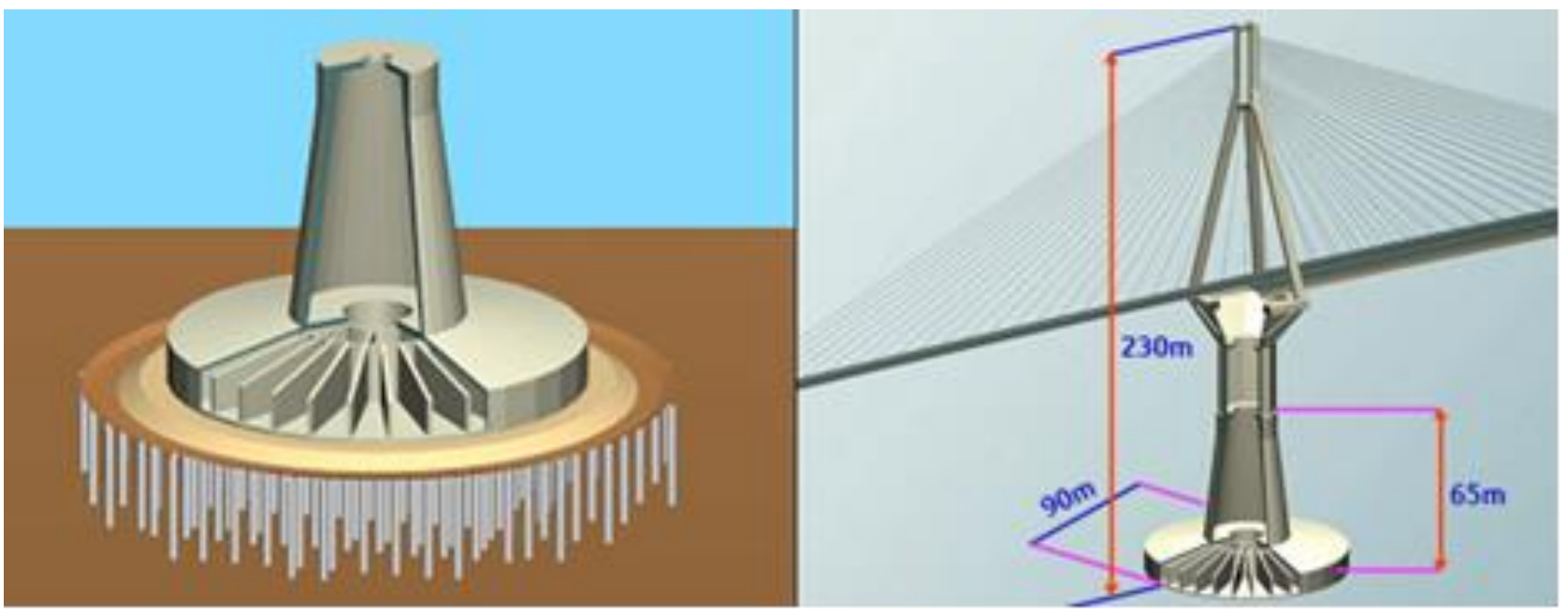

Fig. 11 Pier foundations [29]

The legs, with a cross-section of $4 \times 4$ meters, start from the 4 corners of the pillar base, and connect at the top of the pillar forming a head, thus providing a rigidity which is necessary against asymmetric loads and various operating and seismic forces [6].

The erection of each pier was realized in the water while it was floating above its foundation point (Fig. 12). During its construction, the bigger become the height of the pier the dipper was it going, until it reached its right location on the bottom of the sea.

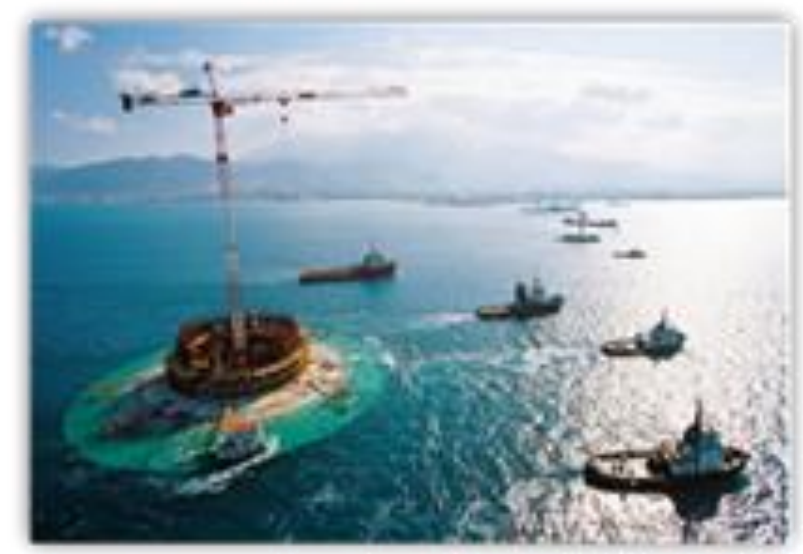

Fig. 12 Pier construction $[6,29]$

\subsubsection{The Three Gorges Dam (China)}

The best solution for supplying China with cheap electricity, was undoubtedly be the Three Gorges Dam (Fig. 13). Built on the Yangtze River, has the size of the Kingdom of Bahrain. It is the world's largest power station as far as the installed capacity $(22,5 \mathrm{GW})$ is concerned. The highest power world record achieved in 2014, during which the dam generated 98.8 TWh, thus sustaining the Chinese economy with cheap and clean electric power [30].

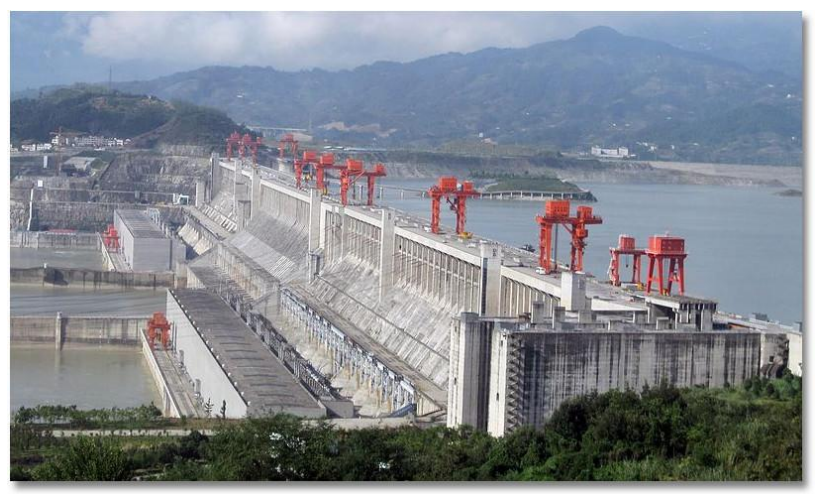

Fig. 13 The Three Gorges Dam (Sep. 2009) [30]

It is 180 meters high, 2,335 meters long while the total area of its reservoir is $1,045 \mathrm{~km}^{2}$ and can flood a total land area of $632 \mathrm{~km}^{2}$. The full volume of water is estimated at $39.3 \mathrm{~km}^{3}$, while its weight is about 42 billion tons! The concentration of such a large amount of water, 180 meters above sea level, results in increasing the Earth's moment of inertia slowing down its rotation. Of course, this effect is very small and according to NASA scientists it only adds 0.06 millionths of a second.

Despite its questionable construction quality, with 32 state of the art large turbine generators it creates a continuous source of power, thus contributing in a reduction of greenhouse gases and many floods that previously destroyed the region. Furthermore, the dam facilitates more than 150 chartered ships each day in the Yangtze River [30]. 


\subsubsection{Kölnbrein Dam (Austria)}

On a natural, steep place, under the Hohe Tauern range, at a $200 \mathrm{~m}$ height, where the Malta Valley spreads, the tallest arch dam in Austria was constructed in the period 1971-1979.

Due to the virgin of nature there were, of course, significant problems in order to carry the necessary materials. For this reason, among other ancillary regional projects, six tunnels were excavated.

Despite the difficult weather conditions (rain, snow and wind) in the valley the workers managed to cope with them. In 1977, the progress of construction had reached a point, where the dam, consisting of 30 columns, started to form its reservoir. At this stage, cracks appeared in the dam while filling with water, as a result of very strong hydrostatic pressure on the central bottom part of the dam, due to its arch type.

Following a series of improvements, in 1979 a second attempt to fill the reservoir was unsuccessful.

A polyurethane resin grout was used in the period 1980-81, to re-grout the joints but the works were not successful, because they were frozen during the next filling attempt.

In the period 1981 - 1983, a plastic sheet-covered concrete blanket was laid on the upstream valley floor behind the dam [31].

The reservoir was eventually able to work safely in 1984 , reaching $90 \%$ of its total capacity.

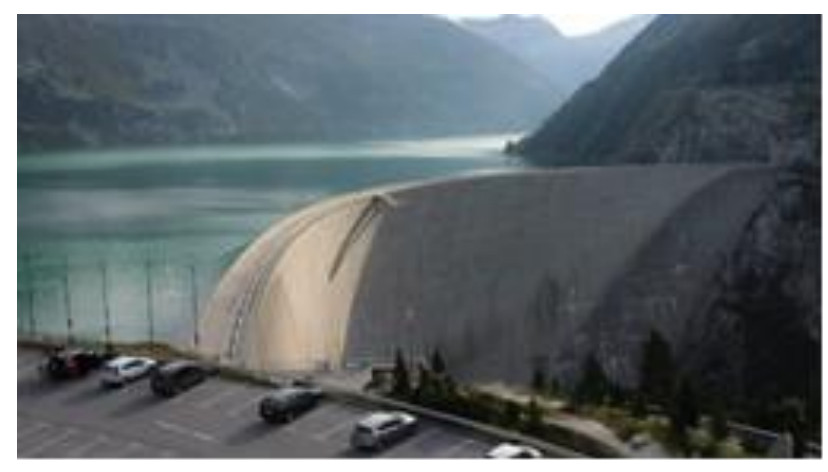

Figure 14. Kölnbrein Dam (Austria) [31]

Of course, the above sheets and the grout curtain had to be repaired and re-grouted accordingly in the future (Fig. 14).

\subsection{Building Projects - Examples of skyscrapers' foundations}

Buildings have always housed a large number of people. With the evolution of the world, and due to the phenomenon of urbanization, societies, to be able to house more people in a smaller area, attempted to build taller buildings - infrastructures, creating skyscrapers [32].

They have many floors and, in most cases, exceed 100 meters, trying day by day and over the years to achieve the impossible for today, i.e. skyscrapers, these tall buildings to really "scratch" the ethers.

\subsubsection{Trump International Hotel and Tower - Chicago, Illinois, USA}

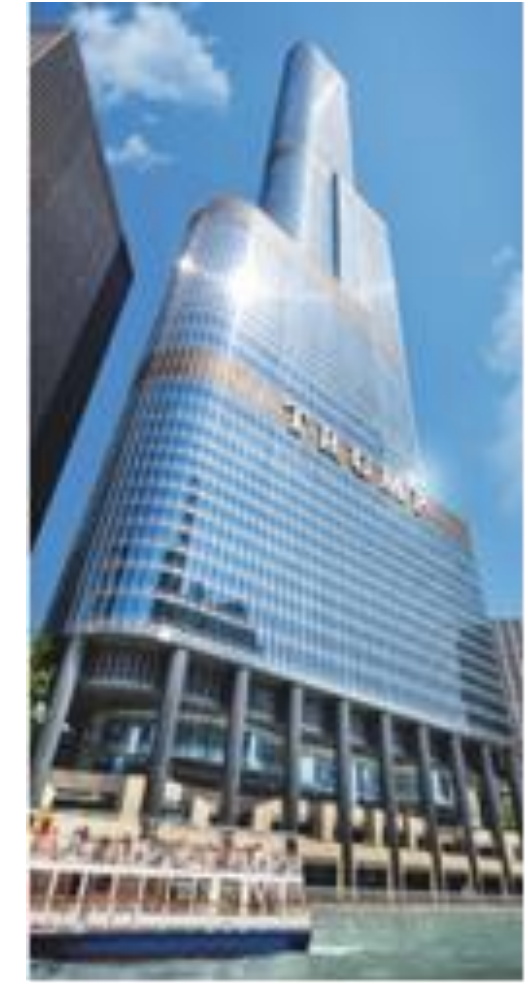

Fig. 15 Trump International Hotel and TowerChicago, Illinois, USA [33]

The 1389-foot-high Trump Tower is a recently added building on the Chicago skyline located on Michigan Avenue. The skyscraper includes mostly houses and offers amazing views to its guests. Skidmore, Owings and Merrill, skyscrapers adorers, designed the $423.4 \mathrm{~m}$ tower in front of the Chicago River. Initially Trump had announced that this building would be tallest in the world. However, the plans had changed after the terrifying attacks on the Twin Towers and so its height was reduced.

The composition of the ground at the site where Trump Tower (Fig. 15) was to be erected did not differ from that of the surrounding area. The subsoil consisted of layers presenting a high level of silt and Limestone Dolomite and Bedrock in an average depth of $34 \mathrm{~m}$ under the current surface of ground $[34,35]$.

In such ground conditions buildings that bear medium loads are mainly erected on belled caisson in 
the hardpan strata, while others, bearing high loads, use a rock-socketed caisson construction [34, 36].

Due to the tremendous loads of the tower, the foundation was laid in collaboration with two large geotechnical groups [34, 37].

Following relevant suggestions, it was decided a hardpan supported belled caisson for the low rise along the retail portions of the work, while the tower would be supported by reinforced concrete caissons, rock-socketed, with permanent steel casings [38].

The rock caisson had to be drilled on the top of the rock and then a permanent steel casing should be inserted and drilled in it, in order to protect from groundwater, the caisson shaft. Then the steel casing was screwed in the rock and sealed with grout [37].

After setting, the bottom of the caisson was drilled or cored up to a certain point, i.e. a minimum of 1800 $\mathrm{mm}$. Obviously this depth has was measured from the sound top point of the rock [36].

The caisson diameter was finally selected to be 3 $\mathrm{m}$, resulting in a reduction of the building's total height [36].

The core of the structure, which was highly loaded, was supported by a reinforced concrete mat $3 \mathrm{~m}$ in thickness (Fig. 16), which transferred the tremendous core load into 24 rock caissons of $3 \mathrm{~m}$ diameter [38].

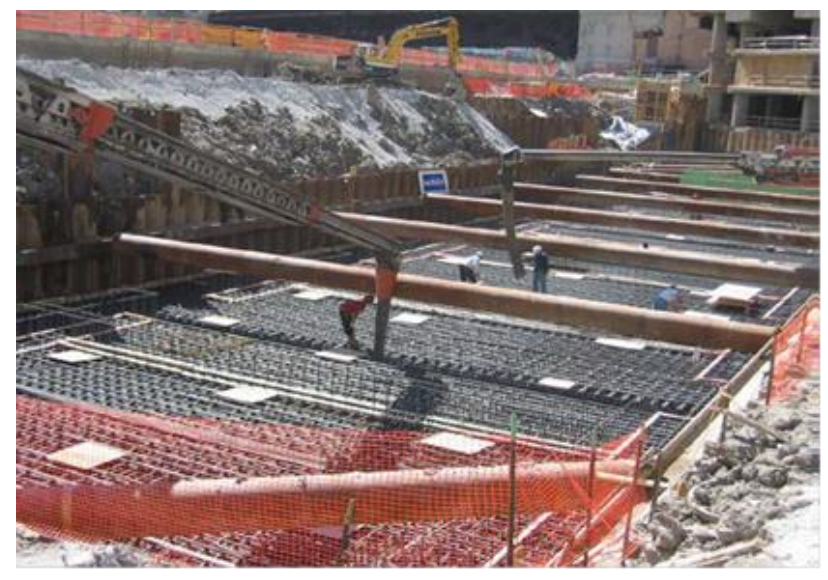

Fig. 16 Foundation works [38]

The peripheral and internal columns were supported by 33 distinct rock caissons, with diameters up to $2.4 \mathrm{~m}$, bonded together by many caisson caps and grade beams [38].

The load carrying capacity of the core was mainly controlled by the corresponding caissons of maximum, $3 \mathrm{~m}$, diameter which were located in the footprint of core flanges [37].

The caissons' bearing capacity was increased through the use of Osterberg Load Test, which was limited used at other places of the City, resulting in a further permission increase of the pressure bearing until $15 \%$.
A test of O-cell was realised with success on a rock caisson in April 2005 [38].

The increased bearing pressure, along with the use of compressive strength $69 \mathrm{MPa}$, was the reason for the tower to increase its height reaching the number of 92 floors. In fact, including mezzanines and basements there were totally 100 framed levels [37, 38].

\subsubsection{Burj Khalifa - Dubai, UAE}

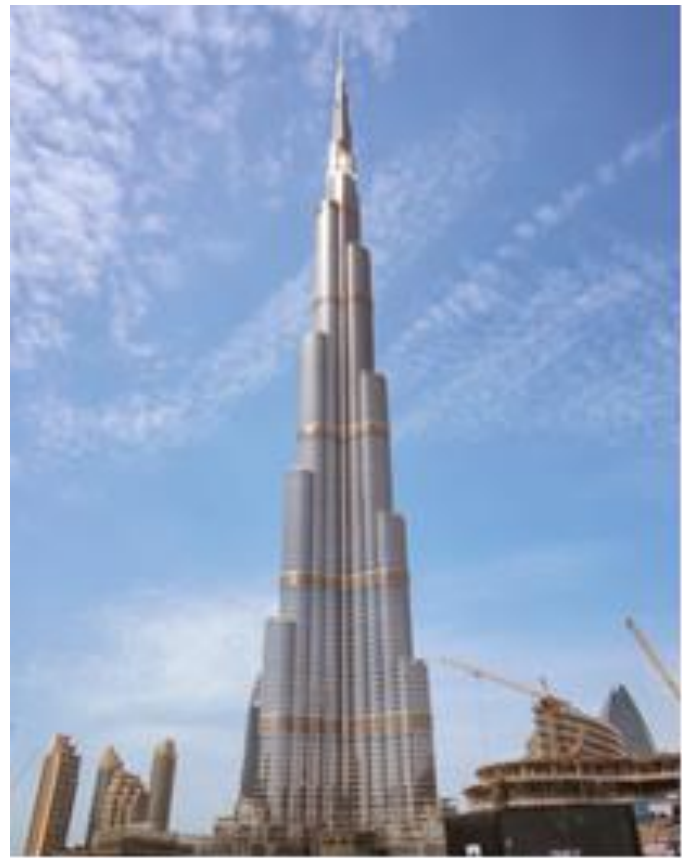

Fig. 17. Burj Khalifa- Dubai, UAE [39]

The foundation of the Khalifa Tower - Dubai, consists of a pile-supported raft [36,40], which is used to dampen subsidence. The soil foundation profile varies along the project from medium to low sand density until loose to moderately loose sandy soils with calcium admixtures $[35,36]$. The horizon aquifer is quite high and only $2 \mathrm{~m}$ below ground level $[37,40]$. The geotechnical research was carried out under the supervision of a team of engineers from the University of Sydney [37], famous for the background knowledge it offers to civil and geotechnical engineers. A remarkable research was carried out in various stages with drillings from 3 to $60 \mathrm{~m}$ and completed with drillings using the crosshole and downhole methods to a depth of $140.6 \mathrm{~m}$ $[35,36,37,40]$. The values of the soil properties $\varphi, c$ and $\mathrm{E}$ were calculated from the geotechnical survey, while at the same time a sedimentation study was carried out. The latter survey resulted in subsidence of 4.6 to $6.0 \mathrm{~cm}[35,37]$, which was considered acceptable for this large project which, notably, carried a total uniform load stress of $1,465 \mathrm{kPa}$. 
$12,500 \mathrm{~m} 3$ of cast concrete C50 [35.37] were needed for the concreting of the tower raft $(3.7 \mathrm{~m}$ thick). The concreting took place in four separate sections and lasted 24 hours. The iron bars were placed according to the study on the raft every $30 \mathrm{~cm}$. in such a way as to omit the 10th bar in order to create a series of "pour enhancement strips" throughout the raft. The intersections of the strips formed $60 \times 60 \mathrm{~cm}$ openings, facilitating the casting, vibration and laying of concrete $[35,36]$. It should be emphasized that due to the thickness of the construction, any different temperatures due to the hydration temperature were delimited for the precise determination of the design and the laying of the concrete. Class C50 concrete was prepared from $40 \%$ fly ash with a water-to-cement ratio of 0.34 [35].

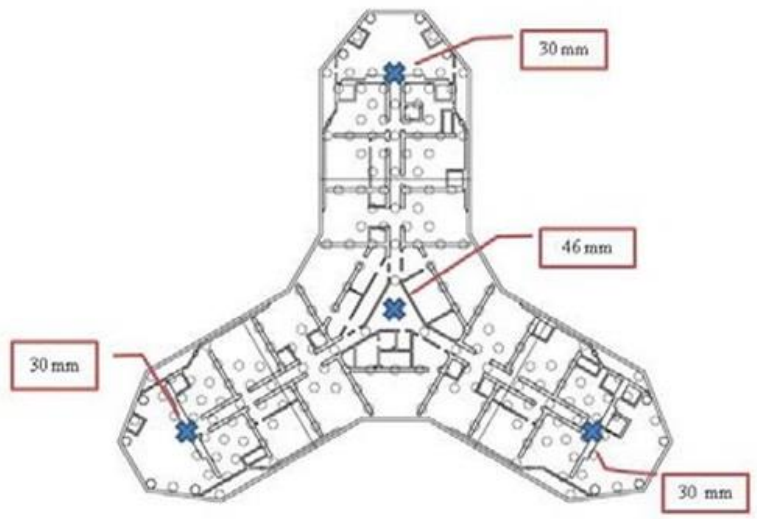

Fig. 18 Raft monitoring key plan

The Tower raft was supported by 194 bored castin-place piles. The piles were approximately $43 \mathrm{~m}$ long, having 1.5 meters diameter and a capacity of 3,000 tons each [35, 37]. Each pillar had a load of 6000 tons, which is the largest pile load in the area [35] while similar tests were performed on piles with a diameter of $0.9 \mathrm{~m}$. It should be noted that it was not possible to accurately estimate the marginal frictional limit resistance, as no pile failure occurred during the tests. [35,36,37]

The high level of the erosive aquifer caused many problems as it contained clods and sulfates on average three times more than seawater [35,36,37]. For this reason, direct anti-corrosion measures were applied to protect the foundation system of the above construction, which included a series of specialized sealing measures of both the foundation plan and the headbands of the piles.

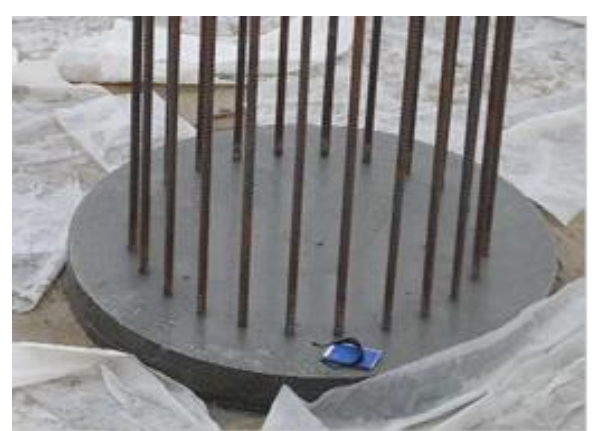

Fig. 19 Pile Head Waterproofing System

This increased the coating of the concrete reinforcement while a universal corrosion protection system was applied using titanium mesh. [35,36,37]. Finally, a controlled permeability formwork lining was used to cover the foundation in order to increase the strength and at the same time reduce the permeability of the concrete $[35,36]$. Finally, for the piles, reinforced self-leveling concrete was used in order to reduce any defects in the construction [37].

\subsubsection{Meru as a Hindu Sacred Building Architecture with a High Roof and Resistant to Earthquakes in Bali, Indonesia}

Meru is a very beautiful sacred building that is built based on the accuracy of proportions, the logic of construction techniques, and the beauty of decoration, which holds fast to the local wisdom of Balinese Traditional Architecture. (Dwijendra, 2020) [49]. It should be emphasized that Meru construction is earthquake resistant construction that has proven its reliability compared to temple buildings or other forms. More specifically it is noteworthy that a very powerful earthquake with enormous power has ever happened in Bali (such as in Seririt District, Buleleng Regency in 1976), where many modern construction buildings have collapsed, but sacred buildings in Bali, especially Meru still stand firmly, strong, stable, and upright. Of greater interest, however, is the manner of construction of the above building described below with the characteristic name of the materials (in parentheses) used to complete the construction. Meru construction with bonding holes reinforced with pegs or wedges without nails. Roof construction with clasps and ties. The bottom frame is a series of four corner pillars and reinforcement, stiffener, and complement constructions. For large Meru, in addition to the angling pole, there is also a side pole. The row poles are another supporting edge of the roof below. As for sub-structures, meru's foundation uses local foundations at the point of placement of the pillar (saka) and a continuous foundation around the boundaries of the rocks which are attached to the rocks and kekarangan (fauna ornaments) (Fig. 20) [49]. 


\subsubsection{High-Performance Concretes Intended for Deep Foundations of Constructions}

We should not miss the reference to the use of materials with a modern and high level of technology that ensures a significant increase in the strength of the foundation and in general the background of the structures.

The term High-Performance Concrete (HPC) is

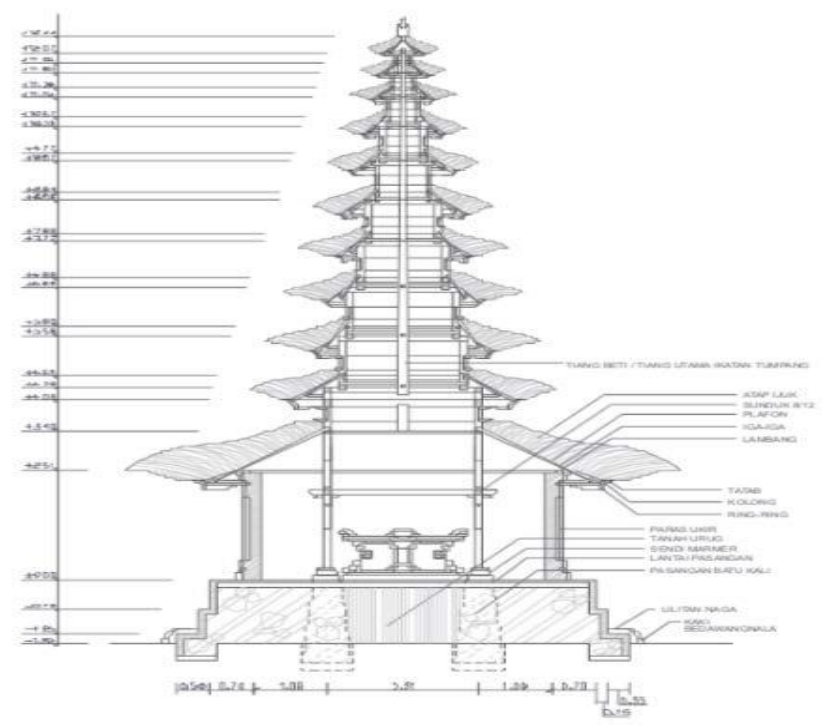

used to describe and denote any concrete admixture that may increase its strength or tightness. One such category of concrete is that used for concreting piles for foundation. Obviously, the piles belong to the category of deep foundations and are applied in large industrial and urban buildings as well as in important infrastructure projects. The principle of application of HPC is based on the creation of foundation piles,

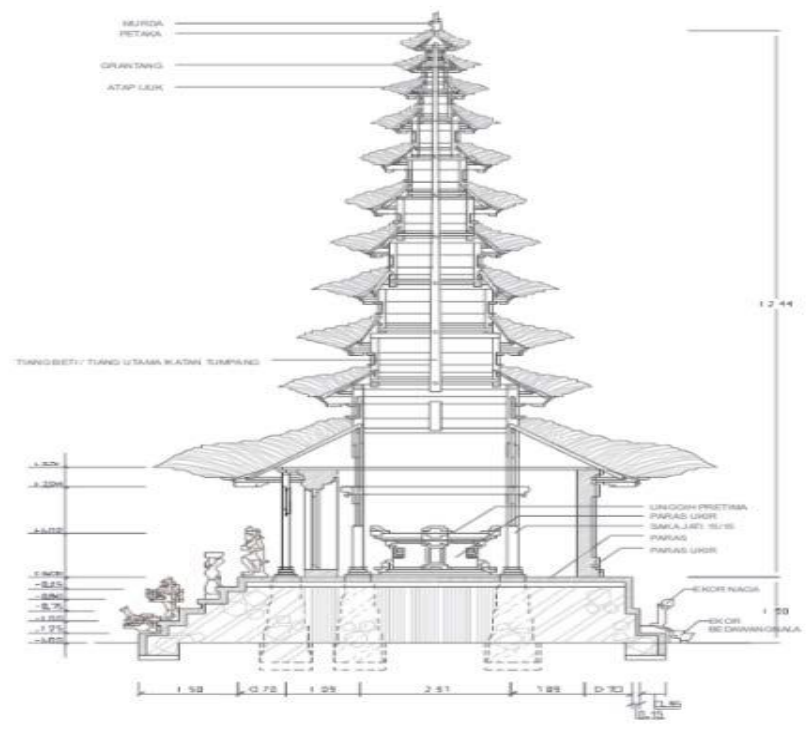

Fig. 20 Structure and Construction of Meru which is Holy and Earthquake Resistant [49]

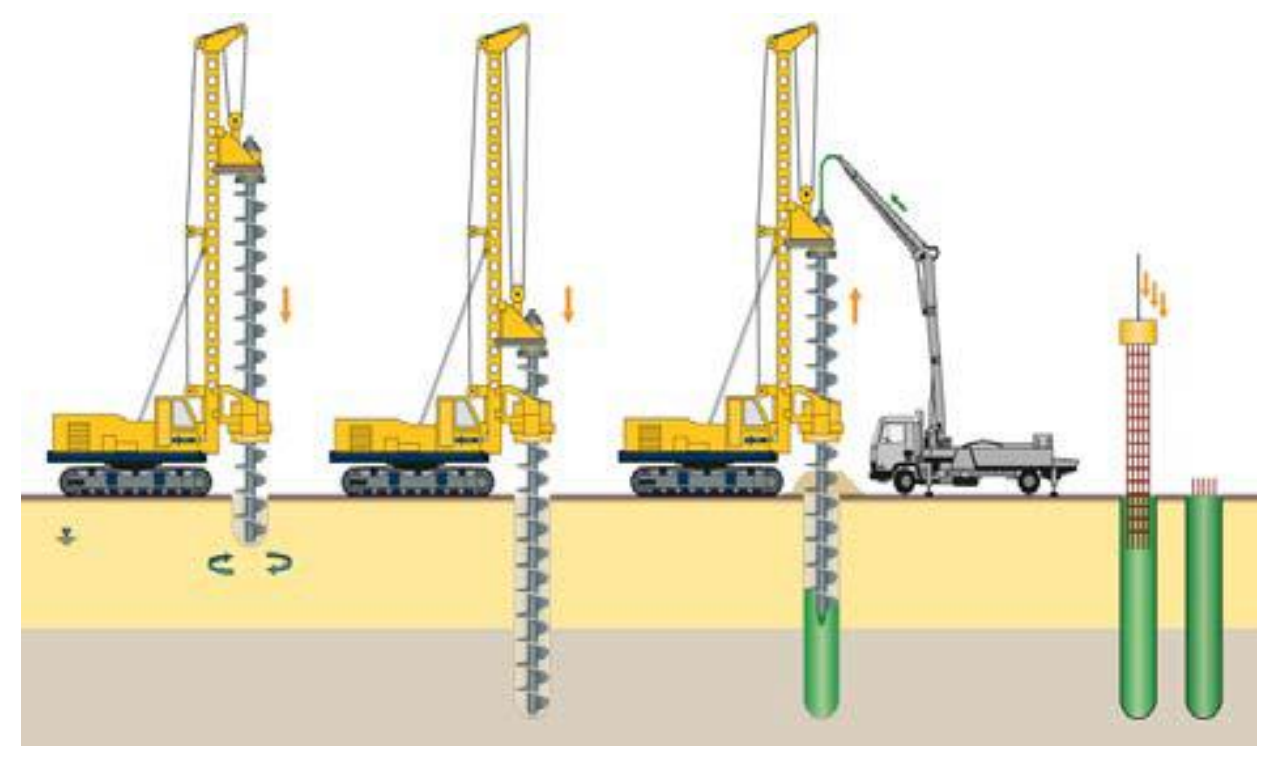

Fig. 21 Scheme of production of bored deep piles

the ends of which penetrate deep into the ground until they meet a stable ground that presents high loadbearing capacity. The length of each pile is calculated from the depth of penetration up to the headband that carries the load of the superstructure. The way to build deep foundations is shown in Figure 21. [50].

\section{Critical Analysis}

An impressive achievement of Architecture and Engineering created the beautiful Øresund Bridge, which connects Denmark with Sweden and the city of Malmo. It is the longest bridge in Europe with both a motorway and a railway, of which, almost the half 
part is underwater, mainly for convenience and safety reasons of the Copenhagen Airport.

For the construction of the bridge supports, there were 4 main towers. The construction of these massive towers was realized in sections. Each one of them was poured and placed using special built rigs.

It must be mentioned that the majority of the bridge large elements - piers and spans- were constructed on land and afterwards tuged out on the corresponding spot of the bridge via a huge floating crane. The pylons were an exception and were cast in situ.

The length of the $4 \mathrm{~km}$ sub-tunnel was covered by concrete elements, which, like piers and spans, were cast on land, and, having tugged out on the proper place, lowered into a trench which was dredged in the sea bottom.

The Bangabandhu Jamuna Bridge is mainly supported on huge tubular steel piles (details are provided in section 4.1.2), which were driven into the riverbed. A strong airlift was used to remove the sand from the piles and replace it with concrete. The above procedure of driving lasted less than one year (19951996)

The bridge has a length of $4.8 \mathrm{~km}$ and serves as a link between the eastern and western parts of the country, while an important part of the infrastructure is the presence of connections with the southern corridor of the railway network of Asia, which will serve the provision of international road and rail connections. Southeast Asia through Central Asia to northern and western Europe.

The pier stems are founded on concrete pile caps, whose shells were precast and in-filled with in-situ reinforced concrete. The reinforced concrete pier stems support pier heads which contain bearings and seismic devices. These allow movement of the deck under normal loading conditions but lock in the event of an earthquake to limit overall seismic loads through the structure and minimize damage.

Due to the strong seismic activity in the area, the Rion-Antirion Bridge needed to be able to withstand an earthquake comparable to the Izmit earthquake which measured 7.4 on the Richter scale (the South Rion coast drifts several millimeters away from the North Antirion coast every year).

A suspended deck acting as a pendulum during an earthquake was the best way to counter such natural forces. Besides, the bridge can sustain the impact of a $180,000 \mathrm{t}$ tanker sailing at $18 \mathrm{kt}$ as well as winds of up to $250 \mathrm{~km} / \mathrm{h}$. Caissons, which form the bases of the piers hold the bridge's pylons, were constructed in a purpose-built dry dock, moved to a wet dock where the concrete was added, and then towed out to the installation area and lowered using tug winches.
Seabed reinforcement (in depths of up to $65 \mathrm{~m}$ ) was achieved by using $2 \mathrm{~m}$ diameter hollow steel pipes 25 $\mathrm{m}$ to $30 \mathrm{~m}$ long. 200 pipes were driven into the seabed by a crane on a tension leg platform, which was installed at every pier location. This was topped with a 3 m-thick, leveled gravel layer. A cone with a diameter of $38 \mathrm{~m}$ formed the lower part of the pier. The pier head itself measures $90 \mathrm{~m}$ in diameter and is believed to be the largest base foundation ever constructed for a bridge. The upper pier shaft with its reverse pyramid shape is $15 \mathrm{~m}$ high and has a $38 \mathrm{~m}$ long square base. Building such a structure involved the implementation of major innovations in terms of construction methods, especially about strengthening the marine subsoil - making this bridge a one-of-akind achievement.

The Three Gorges Dam is the largest construction in the world in its class, having used outrageously large amounts of concrete to meet the needs. This subsoil construction is based on the riverbed with its advantages and disadvantages.

On the other hand, the Kölnbrein Dam has now faced severe difficulties due to the support subsoil and the peculiarity of the construction. That is because the dam is in a "U"- shaped valley instead of the usual "V"-shaped for arch dams; hydrostatic pressure is exceptionally strong on the center-bottom (heel) upstream portion of the dam. As excessive water leaked into lower areas of the dam, the water level was drawn down and engineers increased drainage.

The Trump International Hotel and Tower building is cantilevered into a section of 420-millionyear-old limestone bedrock 110 feet $(33.5 \mathrm{~m})$ underground. It uses 4-foot $(1.2 \mathrm{~m})$-wide stilt-like pillars that were drilled beneath the building. Every 30 feet $(9.1 \mathrm{~m})$ around its perimeter, steel-reinforced concrete was poured into these holes to form the structural support. On top of these caisson shafts and pillars, an 8,400-short-ton $(7,600 \mathrm{t})$ concrete pad foundation was built to support the building's spine. The building has 241 caissons, and most of the caissons only descend 75 feet $(22.9 \mathrm{~m})$ into hard clay. However, 57 of them go an additional 35 feet (10.7 $\mathrm{m})$ into the ground, including 6 feet $(1.8 \mathrm{~m})$ of bedrock. The concrete spine uses five I-beam-shaped walls and exterior columns, narrowing to two as the building rises. Each floor is separated by a concrete slab, and stainless steel, glass, and aluminum panels are attached to each floor. 50,000 short tons $(45,000$ t) of reinforcing steel bars, called rebar, support the hotel. The extensive use of concrete makes the building more fireproof.

Burj Khalifa's construction used totally $330,000 \mathrm{~m}^{3}\left(431,600 \mathrm{yd}^{3}\right)$ of concrete and 55,000 
tones $(61,000$ short tons; 54,000 long tons) of steel rebar, and construction took 22 million manhours. In May 2008 Putzmeister pumped concrete with more than $21 \mathrm{MPa}$ ultimate compressive strength of gravel to surpass the 600 meters weight of the effective area of each column from the foundation to the next fourth level, and the rest was by metal columns jacketed or covered with concrete to a then world record delivery height of $606 \mathrm{~m}(1,988 \mathrm{ft})$, the 156th floor. Three tower cranes were used during construction of the uppermost levels, each capable of lifting a 25-ton load. The remaining structure above was constructed of lighter steel. In 2003, 33 test holes were drilled to study the strength of the bedrock underlying the structure. "Weak to very weak sandstone and siltstone" was found, just meters below the surface. Samples were taken from test holes drilled to a depth of 140 meters, finding weak to very weak rock all the way.

The skyscraper, 827 meters high, is visible from a distance of $100 \mathrm{~km}$ in good weather conditions. It has a total of 24,348 windows and it is noteworthy that the highest floor presents a temperature difference from the first one, 6-7 degrees Celsius. Engineers faced multiple challenges during construction, including strong winds exerting pressure on the tower, which led to more than 40 tests in an aerodynamic tunnel, not only to see how the wind would affect the building, but also to test the cranes, used in construction.

Meru as a Hindu Sacred Building Architecture is from a construction point of view one of the most interesting buildings in the modern world not only for its special architecture but also for its seismic properties. In fact, its resistance to earthquakes has been proven by previous seismic vibrations which, as it is known in the region of Indonesia, show great intensity and accelerations. Meru is a parahyangan building where the shape of the building uses the form of overlapping roofs. The structure of the building uses a very efficient frame structure system to withstand the load in the presence of a pole (saka) as a distributor of vertical loads and sineb-lambang beams, diagonal beams as a pedestal pole (titimamah) as a horizontal load divider. All elements of the structure in addition to their high aesthetics are made with dimensions that are under the procedures or rules of Balinese Traditional Architecture Script. and good quality materials so that their construction can withstand the burden of both wind, earthquake, thermic, and other loads very effective, sturdy, strong and stable [49].

\section{Suggestions-Conclusions}

The following sections present the SuggestionsConclusions that emerged from the research process of this paper and are in line with the goal of the educational effort set by the writing team.

\subsection{Suggestions}

The suggestions of this article refer to the general improvements of the foundations for both the building and the infrastructure projects, depending on basic natural factors, which to a large extent affect the construction background and potentially the whole project. Natural hazards are sudden and dangerously strong, posing serious threats to societies both nationally and sometimes internationally. Today great progress has been done by scientists to predict natural disasters. Hurricanes, for instance, snowstorms tornadoes, and typhoons are often predicted.

On the other hand, it is not uncommon for nature not to warn, wanting to surprise or even test human powers, and achievements against it.

A common phenomenon that directly affects the nature of the technical works is the earthquake, which can occur at any time of the year, without, almost most of the time, any prior indication. Today, to prevent or combat the seismic phenomenon, special springs or elastomer vibration dampers are proposed, due to which tectonic movements can be partially absorbed and thus affect to a lesser extent the upper part of the construction.

Also, in high-rise buildings, the installation or application of viscosity oil dampers, steel stabilizers against buckling along the use of dampers at various levels of these buildings can be highly useful and protective against earthquakes.

At the level of infrastructure projects, greater emphasis should be placed on avoiding and finding ways to deal with geotechnical seismic hazards, such as liquefaction, slope and embankment instability during a seismic event, which may affect a bridge structure and its embankment.

Therefore, the analysis of seismic stability is proposed, not only using the pseudo-static or Newmark earthquake method, but also the finite element or finite difference method.

The latter methods can help to calculate the stresses and deformations that develop in the mass of the slope during the seismic vibration, but mainly they can estimate the permanent seismic displacements which can eventually result in the partial or total destruction of the structures that are grounded.

Particular care is needed in the case where underground gas pipelines follow the slope. In these cases, the pipeline may be subjected to bending 
resulting in significant compression, with a high risk of local buckling, large plastic deformation, and wall rupture. The seismic performance of oil and natural gas steel pipelines embedded in earth slopes presents great uncertainty related both to the earthquake shaking characteristics and to the natural heterogeneity of geomaterials. Slope movements and landslides in general constitute a significant risk to pipelines because they can cause permanent deformations and rupture, resulting in spills and environmental problems. Also, earthquakes may constitute a threat for the structural integrity of buried pipelines. Post-earthquake investigations have demonstrated that most seismic damages to continuous oil and gas steel pipelines were caused by permanent ground deformations such as fault movements, landslides, liquefaction-induced lateral spread [51]. Recent investigations show that if the slope experiences failure followed by large displacements (due to strong shaking and small soil strength), the pipeline may present severe global and local buckling.

The effect of the spatial variability of the soil properties on the permanent seismic movements of the slopes plays an important role [41.42].

Alamanis and Dakoulas (2019) and Alamanis (2020), [43], [44] considered in two-dimensional analyses, the effect of the spatial variability of soil properties on the seismic behavior of energy pipelines embedded in slopes.

Apart from the original constructions [49] that have already been mentioned, modern technologies of material products such as High-Performance Concretes, which significantly increase the strength of concrete in the background of constructions, have a special place [50].

Modern technology trends lead to new materials that will reinforce the strength of the foundations. The research effort so far has given us materials like:

- Bioconcrete is cited to be self-healing and more durable because it incorporates this living element,

- Ferrock cited as "less expensive, stronger, more flexible and carbon negative concrete", may be the solution for environmentally-conscious builders,

- New chemical called a "super-super" plasticizer makes it possible to pour a mix that flows almost like water but retains structural integrity. (Normally, a too-thin mix allows the aggregate to settle to the bottom before the concrete cures, resulting in a weaker wall).

Lightweight forms made of high-density polyethylene fabric can also be used. These flexible fabric systems conform easily to sloping and uneven sites, which simplifies excavation, and the fabric stays in place as a built-in damp-proofing membrane. The bulging sides of the finished footings also help to divert water away from the foundation.

Finally, apart from the above, it is estimated that the research effort should focus on the experimental investigation of the post-seismic bearing capacity of partially improved fluidizable soil.

However, it must be emphasized that each project case is unique and to ensure an ideal behavior of the construction, the design must be developed according to the data provided by nature, following the existing scientific theory and experience for the installation of the project, and thus ultimately pioneering solutions and methods beyond the usual techniques, which may be the basis for starting a new horizon.

\subsection{Conclusions}

Modern architects and engineers adopt a global character where high-rise buildings, elaborate reconstruction techniques, and separate - for each application - foundations, both in buildings and infrastructure are some of the modern and most futuristic features.

The following conclusions briefly and comprehensively describe the findings of the research work. In building projects, their forms and types are a function of the societies to which they belong. An important factor of dependence for each construction is the earthquake. Japan was a leading "contractor" in innovative building projects, especially at the level of small buildings, after the Kobe earthquake in 1995, thus achieving a level of structural strength above 7 on the Richter scale.

The response of a building to an earthquake is vibrations in the form of sinusoidal motion. For highrise buildings, a factor to be avoided is the wide influence of wind load.

More specifically: It is known that the load-bearing structure (LBS) of very tall buildings is made out of metal frame. According to the regulation, the LBS of a building is subject to static and dynamic analysis so as to lead to correct dimensioning. Dynamic analysis considers the lateral loads that strain the construction. There are two types of lateral loads, wind and seismic loads. Especially for a tall building we must consider the slenderness, which is a crucial index for the flexibility, that affects the buckling behaviour. In general buildings suffer from lateral loads, resulting from wind and earthquake [52].

In fact, it is noteworthy that in high-rise metal buildings, the wind pressure puts more strain on the 
building than a large seismic vibration. The dynamic behaviour of the building must therefore be able to avoid 'the wide influence of wind load', so that we do not have coordination that can lead to individual failures or even collapse.

Thus, the use of technologically advanced devices and damping methods is quite common, with the only commonly accepted parameter not changing the building's localization of the centre of gravity. This is the main reason that the existing load-bearing core of the skyscrapers is usually a large steel frame which incorporates steel columns filled with concrete.

In the case of The Burj Khalifa (Dubai) tower, the necessary strength for the construction of the tallest building in the world was provided by the pilesupported mat [45].

But in the case of the Trump Tower (Chicago), the strength and constructability of the caissons along with the bedrock strata were the key elements, that allowed for a complicated and very heavy tower of reinforced concrete [46].

The functionality of infrastructure projects is extremely important considering how life would be like if an individual and potential citizen were, for instance, responsible for, pumping and purifying water and then finding ways to dispose of the waste. Thus, for each case, the development of infrastructure projects facilitates the achievement of the goal for a specific purpose each time.

The Øresund Bridge (Sweden) is unique in its kind, as it combines in special way stability with the sea bottom and excellent service to the nearby airport, achieving thus a clear operation of a large highway on the upper deck above sea level along with a railway on its lower deck. Its foundation was actively armed after many attempts, as at first, it seemed to be an impossible operation.

The Bangabandhu Jamuna Bridge (Bangladesh) was a successful implementation covering the needs in a country with various living problems in transporting people, food, goods, and gas. The construction was achieved due to the adequate preparatory work (ex-ante design actions, preselection of contractors, procurement of materials, recruitment of consultants, and government approvals), creating thus a superstructure, consisting of a highway and a railway. The superstructure has been designed, knowing the great forces from dead and mobile loads, combined with the effects of wind and forces of nature, such as loads created due to the movement of water from the river Jamuna.

The Rion-Antirion (renamed Charilaos Trikoupis) Bridge (Greece) is unquestionably a highly modern construction system that simultaneously combines a series of world-wide records, i.e.:
- The span in that time was the longest of any cablestayed bridge,

- The challenges that faces are capable to destroy any ordinary bridge,

- An earthquake fault-line cuts the bridge to the middle,

- The water is too deep,

- The sea-bed is too soft, and

- It has the largest bridge foundations.

The bridge system provides continuous monitoring of its condition, through the installation of hundreds of sensors on the deck and pylons, wiring, and ground to detect wind and seismic vibrations, voltage meters and load cells in the wiring and its connecting plates, sensors measuring the thermal displacement at the expansion joints on the deck, and other sensors to inspect the level of water at the base of pylons, for filtration detection, temperature sensors at the deck, sensors in wiring for motion measurement and not only [47].

The Three Gorges Dam (China), is the most expensive dam in the world and the second most expensive construction project in the world after the space station in orbit. Thus, having these gigantic features, the foundation of the dam is automatically constructed in such a way that it can withstand the heavy loads that reach the construction, thus strengthening the foundation subsoil, aiming at artificially minimizing the encroachment of this and the surrounding natural environment.

Kölnbrein Dam (Austria), is a special construction located between mountains. The large number of problems created during the construction is the main reason for exacerbating the subsequent maintenance of its functionality. The tank water is intended to generate electricity. Due to the fact that the area surrounding the dam, i.e. the catchment can supply around half of the water required to maintain its reservoir levels, several pumps are used to replenish storage capacity. The above pumps fill the tank working in periods of low power demand [48]. If the demand of power is high, then the system accepts water to generate the necessary electricity.

The construction of the Meru as a Hindu Sacred Building Architecture can withstand earthquake, wind, thermic, and other loads. The completion of some structural and construction elements gives a very beautiful shape so that the elements are not only sturdy and stable to withstand the load but also have a very high aesthetic value. The structure and construction of Meru as a building, has a sacred and symbolic meaning apart from the fact that with respect to other 'sacred buildings', it has proven its reliability on earthquakes [49]. 
It is worthwhile to emphasize that special attention has to be paid on the high-quality of concrete, steel products and not only, which are designed for piles and other elements of foundation in the procedure of production in order to increase the strength and water tightness of concrete [50].

Finally, the results of the research demonstrate the important strategies selected for the design of the foundations presented in the above work as well as the advanced technology used during their construction.

The engineer, however, by nature, wants to prevent and overcome as much as possible the function of nature. This is a reason for continuous efforts to find innovative ideas - techniques to reach the highest goal he sets each time, thus calculating all the parameters to complete any project under construction.

\section{References}

[1] Chen Wai-Fah, McCarron William, "Bearing capacity of shallow foundations", Foundation Engineering Handbook, pp. 144-165, 1999.

[2] Das Braja, "Principles of Foundation Engineering", 6th edition, 2007.

[3] Barnes Graham, "Training - Principles and Applications", Greek rendition, 2001.

[4] Gavrilaki Aikaterini, Chiotis Dimitrios, "Methods of strengthening foundation data", Proceedings of the 16th Student Conference "Construction Repairs", 2010.

[5] Metaxas Ilias, Koumoulos Dimitrios, Korgialos Athanasios, "Improvement of foundation conditions through bearing on individual slabs on piles in soft and liquefied soils", Proceedings of the 6th PanHellenic Conference of Geotechnical and Geoenvironmental Engineering, 2010.

[6] Papadimitriou Emmanouil, "Thesis: Civil Engineering infrastructure foundations applied to various foundations of engineering structures", 2019.

[7] Bowles Joseph, "Foundation Analysis and Design", 5th edition, McGrow-Hill, 1997.

[8] Building Foundation in Venice, in an earlier period - Venice engineering in earlier period, Accessed on 13/11/2020, https://sites.google.com/site/engineeringvenice/ ?tmpl=\%2Fsystem $\% 2$ Fapp $\% 2$ Ftemplates $\% 2 \mathrm{Fp}$ rint $\% 2 \mathrm{~F} \&$ showPrintDialog $=1$

[9] Finn Paul, Ouellette Jesse, Hutchinson Katie, Muller Ryan, "The Building Blocks of Venice
Preserving knowledge of a city's infrastructure and maintenance", WPI, 2011.

[10] Day Robert, "Foundation Engineering Handbook", McGrow-Hill Companies, 2006.

[11] Comodromos Aimilios, "Foundations supports", Boundary equilibrium - arithmetic methods, 2012.

[12] Jeong Sangseom, "Nonlinear three-dimensional analysis of down drag on pile groups", Ph.D. Thesis, 1992.

[13] Fleming, W.G.K, Weltman, A.J, Randolph, M. F., Elson W.K., "Riling Engineering", 1985.

[14] Belidor Bernard Forest, "La Science des ingenieurs dans la conduit des travaux des fortifications et d' architecture civile", Charlew Antoine Jombert, 1739.

[15] Garcia Gamallo, Ana Maria, "The evolution of traditional types of building a foundation prior to the first industrial revolution", First International Congress on Construction History, pp. 943-956. 2003.

[16] The Øresund Bridge - Flickr - , Accessed on $13 / 11 / 2020$, https://www.flickr.com/photos/pfn/14491037985/

[17] "Prairie Sets SCC Record in the Heart of the City", Concrete Products, pp. 6, 2005.

[18] Ostenfeld Klaus, Steenfelt Jørgen, Pedersen Flemming, Sørensen Carsten, Cowl A/C (2003). Lyngby. Denmark. Transcendent foundation solutions - the cross-pollination of scientific and industrial disciplines to overcome economic and technical challenges in the foundation of large bridge structures. 75th anniversary of $\mathrm{K}$. Terzaghi's "Erdbaumechanik".

[19] Biggart, A.R., Rivière, J-P., Sternath, R. (1993). Storebælt Railway Tunnel - Construction. Proc. Int. Symposium on Technology of Bored Tunnels under deep Waterways, Copenhagen, Teknisk Forlag, pp. 63-93.

[20] Bergdahl U., Steenfelt Jorgen (1994). Digest report on Strength and Deformation Properties of Copenhagen Limestone, Report No. 2-9405244, Danish Geotechnical Institute and Swedish Geotechnical Institute.

[21] Knudsen Cristian, Andersen Cristian., Foged Niels, Jacobsen Peter Roll, Larsen B. (1995). Stratigraphy and engineering geology of København Limestone, Proc.11th European Conference on Soil Mechanics and Foundation Eng., Vol. 5, pp. 5.117-5.126. Copenhagen.

[22] Tunnel of The Øresund Bridge - Vinci Construction Projets, Accessed on 13/11/2020, https://www.vinci-constructionprojets.com/en/realisations/oresund-tunnel/ 
[23] Sørensen Carsten Steen, Clausen Carl J. Frimann, Andersen Henrik, "Bearing Capacity Analyses for the Great Belt East Bridge Anchor Blocks", Proc. Limit state design in geotechnical engineering, Vol. 1, pp. 305-312, 1993.

[24] Klitten Kurt, Ploug Cristian, Olsen Henric, "Geophysical log-stratigraphy of the København Limestone", Proc. 11th European Conference on Soil Mechanics and Foundation Engineering, Vol. 5, pp. 5.127- 5.134, 1995.

[25] Clausen Carl J. Frimann, "A Comparison of Bearing Capacities by Eurocode 7 and Two Limit Equilibrium Computer Programs", Reports 9706-1, 1997.

[26] Barr Joe, Farooq Abdoul, Guest Steve, "Foundations of the Jamuna Bridge", Foundations for Major Bridges: Design and Construction, 1999.

[27] The Bangabandhu Jamuna Bridge, "Banglapedia - The National Encyclopedia of Bangladesh", 2020.

[28] Rio - Antirrio Bridge - TITAN GREECE, Accessed on 13/11/2020, https://www.titan.gr/el/proionta-kaiyphresies/endeiktika-erga/ergo/rio-antiriobrdige.

[29] Rio - Antirrio bridge, Accessed on 13/11/2020, https://www.gefyra.gr/bridge/Meleth-Kataskeuh/

[30] Sturman Catherine, "Building the Three Gorges Dam", Global Construction Magazine, Accessed on 13/11/2020, https://www.constructionglobal.com/constructionprojects/building-the-three-gorges-dam

[31] Lombardi Giovanni, "Kolnbrein dam: an unusual solution for an unusual problem", Water Power \& Dam Construction, 1991.

[32] Baker F. William, Brown Cristian, Sinn Richard, "Structural Analysis and Design of the World's Tallest Reinforced Concrete Building", International Conference on Multi-Purpose High-Rise Towers and Tall Buildings, 2007.

[33] THE TRUMP ORGANIZATION, Accessed on $13 / 11 / 2020$,

https://en.wikipedia.org/wiki/The_Trump_Orga nization

[34] Baker F. William, Korista Stan, Sinn Richard, Pennings K., Rankin Dane, "Trump International Hotel and Tower", Concrete International, pp. 28-32, 2006.

[35] "Burj Dubai Development, Dubai, UAE: Geotechnical Assessment Report", Hyder Construction, 2003

[36] Baker F. William, Pawlikowski James, B.S. Young, "The Challenges in Designing the
World's Tallest Structure: The Burj Dubai Tower", ASCE/SEI Structures Congress, 2007.

[37] Baker F. William, Brown Christopher, Pawlikowski J. James, Rankin S. Dane, "Tall Buildings and Their Foundations: Three Examples", Seventh International Conference on Case Histories in Geotechnical Engineering, 2013.

[38] "Subsurface Exploration and Geotechnical Engineering Analysis and Report for the Trump International Hotel \& Tower, $401 \mathrm{~N}$. Wabash Avenue, Chicago, IL", STS Consultants, 2004.

[39] BURJ KHALIFA- DUBAI, UAE, Accessed on 13/11/2020,

https://www.flickr.com/photos/garethwrayphot ography/16614854988

[40] Baker F. William, Korista Stan, Novak Laurence, Pawlikowski J. James, Young Brandley, "Creep \& Shrinkage and the Design of Supertall Buildings- A Case Study: The Burj Dubai Tower", ACI SP-246, 2007.

[41] Alamanis Nikolaos, Dakoulas Panagiotis, "Effect of spatial variability of soil properties on the stability and permanent seismic displacements of highway slopes", The 17th European Conference on Soil Mechanics and Geotechnical Engineering, 2019.

[42] Papageorgiou Grigirios, Alamanis Nikolaos, Xafoulis Nikolaos, "Acceptable movements of road embankments", Electronic Journal of Structural Engineering, pp 30-32, 2019.

[43] Alamanis Nikolaos, Dakoulas Panos, "Simulation of random soil properties by the Local Average Subdivision method and engineering applications", Energy Systems, Springer, Print ISSN 1868-3967, 2019.

[44] Alamanis Nikolaos, "Influence of random soil strength properties on the earthquake vulnerability of slopes with embedded oil and natural gas pipelines", Energy Systems, Springer, ISSN 1868-3967 p.p 1-21, 2020, DOI 10.1007/s12667-020-00394-9.

[45] "Burj Dubai Development, Dubai, UAE: Geotechnical Assessment Report", Hyder Construction, 2003.

[46] "Subsurface Exploration and Geotechincal Engineering Analysis and Report for the Trump International Hotel \& Tower, $401 \mathrm{~N}$. Wabash Avenue, Chicago, IL", STS Consultants, 2004.

[47] "Monitoring the Structural Health of the RionAntirion Bridge Using the LabVIEW Real-Time Module - Solutions - National Instruments", Sine.ni.com.

[48] Langdon John, "Kölnbreinsperre". Archived from the original on 24 March 2012, 2008. 
[49] Ngakan Ketut Acwin Dwijendra, "Meru as a Hindu Sacred Building Architecture with a High Roof and Resistant to Earthquakes in Bali, Indonesia" Civil Engineering and Architecture 8(3): 350-358, 2020 http://www.hrpub.org DOI: 10.13189/cea.2020.080319, 2020.

[50] Tazky Martin, Hela Rudolf, "High-Performance Concretes Intended for Deep Foundations of Constructions" Civil Engineering and Architecture $\quad 8(2): \quad 46-54, \quad 2020$ http:/www.hrpub.org DOI: 10.13189/cea.2020.080202, 2020.

[51] Vazouras Polynikis, Karamanos Spyros and Dakoulas Panagiotis., "Finite Element Analysis of Buried Steel Pipelines Under Strike-Slip Fault Displacements", Soil Dynamics and Earthquake Engineering, (2010), Vol. 30, No. 11, pp. 13611376.

[52] Naguib M., Agag Y. E., El Madawy Mohmaed E., Eman Sharaf, "Dynamic Analysis of High Rise Buildings Using Conjugate Gradient Method" International Journal of Scientific Engineering and Research (IJSER) Volume 7 Issue 5, p.p 37-45, May 2019, ISSN (Online) : 2347-3878, Paper ID: 20051901, 2019.

\section{Creative Commons Attribution License 4.0 (Attribution 4.0 International, CC BY 4.0)}

This article is published under the terms of the Creative Commons Attribution License 4.0 https://creativecommons.org/licenses/by/4.0/deed.en_US 